Philosophical Issues, 16, Philosophy of Language, 2006

\title{
DESCRIPTIONS WITH ADVERBS OF QUANTIFICATION
}

\author{
Delia Graff Fara \\ Princeton University
}

In "Descriptions as Predicates" (Fara 2001) I argued that definite and indefinite descriptions should be given a uniform semantic treatment as predicates rather than as quantifier phrases. The aim of the current paper is to clarify and elaborate one of the arguments for the descriptions-aspredicates view, one that concerns the interaction of descriptions with adverbs of quantification.

\section{First Preface: The Semantics of Descriptions as Predicates}

I'll take it that the semantic value of a predicate is a function of type $\langle e, t\rangle$, that is, a function from entities to truth values. I'll take the extension of such a function to be the set of entities the function assigns the value true to, and the extension of a predicate (denoted by putting double brackets around the predicate) to be the extension of the function that is that predicate's semantic value. Assuming that there are only two truth values, and that the semantic value of a predicate is defined for every entity, we can indicate what semantic value a predicate has by saying what the extension of that predicate is. Indefinite descriptions constitute the simplest case:

(1) $\llbracket{ }^{\circ} \mathrm{a} G^{\prime} \rrbracket=\llbracket G \rrbracket .^{1}$

On the descriptions-as-predicates view, the extension of an indefinite description is just the extension of the predicative complement of the indefinite article.

If we follow Russell, as I will, in taking definite descriptions to have a built-in uniqueness condition that is "proffered rather than presupposed" (to use Craige Roberts's nice phrase), then we could let the extension of a definite 
description 'the $F$ ' be the extension of $F$, if that is a singleton set, and the empty set otherwise. But in order to accommodate the use of the definite article with mass nouns and plural count nouns, which typically do not have singleton extensions, I prefer to adapt Richard Sharvy's generalization of Russell's uniqueness condition to the descriptions-as-predicates proposal, as follows:

(2) $\llbracket$ 'the $F^{\prime} \rrbracket=\{x \in \llbracket F \rrbracket: \forall y \in \llbracket F \rrbracket(y \leq x)\}$.

We may read this as saying that the extension of a definite description 'the $F^{\prime}$ 'is the singleton set consisting of the maximal member of the extension of $F$, if there is one, and is the empty set otherwise. The maximal member of the extension of $F$ is that member of the extension of $F$ that has every other member as a "part."

The use of the word "part" here may be somewhat misleading, but I'll continue to refer to the relation expressed by ' $\leq$ ' as a parthood relation, with the understanding that a different relation might be involved for different choices of $F$, and that calling this relation "parthood" might not be quite accurate for some of these choices.

When $F$ is a plural count noun such as women, the relation can be understood as the relation of being a sub-plurality of. A singular count noun such as 'woman' will have in its extension each individual woman, none of whom will be, in any relevant sense, a "part" of any other; while its pluralization 'women' will, on Sharvy's proposal, have in its extension every plurality of women, each of which is a "part" of (in the sense of being a sub-plurality of) the plurality of all the women there are. ${ }^{2}$ So on the predicate version of Sharvy's proposal, the extension of 'the woman' will either be empty or contain exactly one woman if there are no others; while the extension of 'the women' will either be empty or contain the one (maximal) plurality consisting of all the women there are if there are any at all. If we further take numeral words to be predicate-modifiers, ${ }^{3}$ so that the extension of 'two women', for example, will be that subset of the extension of 'women' that contains every two-membered plurality of women, then the semantic proposals above for plurals, numeral words and the definite article yield the following desirable results, assuming that there are just three women, Ana, Bea and Carlita: ${ }^{4}$

(3) $\llbracket{ }^{\prime}$ woman' $\rrbracket=\{A, B, C\}$,

(4) 【'the woman' $=\varnothing$,

(5) $\llbracket{ }^{6}$ women' $\rrbracket=\{A+B, A+C, B+C, A+B+C\},{ }^{5}$

(6) $\llbracket$ 'the women' $\rrbracket=\{A+B+C\}$,

(7) $\llbracket$ 'two women' $=\{A+B, A+C, B+C\}$,

(8) 【'the two women' $=\emptyset$, 
(9) 【'three women' $=\{A+B+C\}$,

(10) 【'the three women’ $=\{A+B+C\}$.

When $F$ is a mass noun, the relation expressed by ' $\leq$ ' can be understood as the relation of being a sub-portion of. With Sharvy, I'll take a mass noun such as 'water' to be a predicate true of every portion of water, and a modified mass noun such as 'water in my bathtub' to be a predicate true of every portion of water in my bathtub. The definite descriptions 'the water' and 'the water in my bathtub' then each have singleton extensions (assuming that my bathtub has some water in it), containing, respectively, all the water there is, and all the water in my bathtub.

There's an interesting metaphysical question whether the relations being a sub-plurality of and being a sub-portion of can be viewed as two subspecies of the parthood relation, and if so, whether we can view the expression ' $\leq$ ' as univocally standing for the parthood relation (perhaps better described as the relation being some of) in the above statement of the semantics for the definite article. I'm inclined to think that the answer to the second question here is 'no', no matter what the answer to the first is. One reason concerns the following sort of example, discussed by Sharvy. Suppose we have in a seminar room two tables $A$ and $B$ pushed together to form a third table $C$. Then the extension of 'table', restricted to the things in this room, is $\{A, B, C\}$. A question then arises what the extension of 'the table' is to be on the current proposal. Table $C$ has the property of being a parthood-maximal member of the extension of 'table'; so if we therefore take it to be a $\leq$-maximal member, then the description 'the table' (restricted to the things in this room) will be a "proper" description, with $\{C\}$ as its extension. Sharvy was happy to accept this consequence; but I am not, for reasons I won't go into, since they're too distantly related to the point of this paper. My view is that 'the table' has an empty extension here since there are three tables in the room in question, and so that any felicitous use of 'the table' here has to be dealt with on the general model of "incomplete" descriptions. Given this view, we're required to deny that ' $\leq$ ' can be interpreted univocally as standing for the parthood relation. A second reason for denying this will emerge in the next section.

\section{Second Preface: The Logical Form of Descriptions as Predicates}

The present view provides sentences containing descriptions in predicative position after the copula 'be' with a straightforward semantics. If the subject term of such a sentence is an expression of type $e$, that is, an entity-denoting expression, then the value of the sentence as a whole is the value yielded by applying the function that is the semantic value of the 
description to the semantic value of the subject expression; equivalently (given assumptions mentioned at the outset), the sentence is true just in case the semantic value of the subject expression is in the extension of the description. The following serve as examples:

(11) Hillary is a woman,

(12) Hilary is not a woman,

(13) Ana is the woman I met yesterday,

(14) Max is not the owner,

(15) Ana and Bea are the two women I met yesterday.

The interpretation of (11) through (15) proceeds as just outlined given some minimal assumptions. First, I assume that the the 'to be' verbs here are the 'be' of predication and have no semantic value. Second, for negative sentences such as (12) and (14) I assume that the 'not' appearing after 'be' is semantically an operator on the entire sentence, so that (12), for example, has a logical form like '[not [Hilary [a woman]]', and is assigned the truthconditions represented by its standard predicate-calculus paraphrase, ' $\neg W h$ '. The Russellian, in contrast takes 'be' here to be the 'be' of identity and, in the absence of supplemental syntactic principles, assigns two logical forms to (12), corresponding to the predicate-calculus paraphrases ' $\neg \exists x(W x \wedge h=x)$ ' and ' $\exists x(W x \wedge \neg h=x)$ '. Only the first of these, which is equivalent to the simple ' $\neg W h$ ', represents appropriate truth conditions for (12). ${ }^{6}$ Third, I take it that conjoined names, such as 'Ana and Bea' in (16), denote a pluralityrepresented here as the sum Ana+Bea.

The treatment of descriptions as predicates occurring in the argument position of other predicates, as in (16), is somewhat more involved.

(16) The singer smokes.

Before sketching this treatment, I need to step back temporarily to set out the assumptions I'll be making about the syntax and semantics of quantification in English and how to represent it.

The logical forms of sentences containing quantifier phrases will be represented using restricted quantifiers and complex predicates formed by abstraction, following the model of Barwise \& Cooper (1981). A quantifier phrase is represented as a "restricted quantifier," formed by prefixing a oneplace predicate with a quantificational determiner, as in '[some : man]'. I enclose the restricted quantifier in square brackets and use a colon to mark the separation between determiner and predicate. A complex predicate is formed by prefixing an open sentence with a variable-binding abstraction operator, as in ' $\hat{x} x$ smokes'. A restricted quantifier combines with a one-place predicate (complex or not) to form a sentence. ${ }^{7}$ Examples will help to 
illustrate; the gloss below the first logical form indicates how it is to be read:

(17) Juan loves every man, [every : man] $\hat{x}$ Juan loves $x$,

Every man is an $x$ such that Juan loves $x$;

(18) Some man smokes,

[some : man] $\hat{x} x$ smokes.

There are two main advantages to using this notation in preference to the restricted-quantifier notation familiar to readers of Stephen Neale's (1990) Descriptions, where the logical forms of (17) and (18) are represented as follows:

(19) [every $x: \operatorname{man} x]$ Juan loves $x$,

(20) [some $x: \operatorname{man} x] x$ smokes.

One advantage is that by separating out the variable-binding function from quantification, by means of predicate abstraction, the quantifier phrases in (17) and (18) may straightforwardly be treated not only as syntactic constituents but also as semantic constituents of the whole. I take it that the semantic value of a quantifier phrase is a function of type $\langle\langle e, t\rangle, t\rangle$, a "generalized quantifier" in Barwise \& Cooper's (1981) sense. ${ }^{8}$ The semantic value of a quantifier phrase of the form 'every $F$ ' is that type $\langle\langle e, t\rangle, t\rangle$ function that assigns the value true to a type $\langle e, t\rangle$ function just in case its extension contains everything in $\llbracket F \rrbracket .{ }^{9}$ Similarly, the semantic value of a quantifier phrase of the form 'some $F$ ' is that type $\langle\langle e, t\rangle, t\rangle$ function that assigns the value true to a type $\langle e, t\rangle$ function just in case its extension contains something in $\llbracket F \rrbracket$. A predicate abstract such as ' $\hat{x}$ Juan loves $x$ ' has a predicate-type semantic value whose extension consists of those things that, when assigned to the variable $x$, render the open sentence 'Juan loves $x$ ' true. The truth values of (17) and (18) can now be computed compositionally from their logical forms.

A second advantage is that the logical forms in (17) and (18) are virtually identical to the LF-level syntactic structures assigned to these sentences on at least one popular treatment of the syntax of natural-language quantification (namely that defended in Heim \& Kratzer (1998)), and so can be straightforwardly conceived as being derived from the surface forms of English sentences by transformational rules that are reasonably well accepted by linguists working in the tradition of transformational grammar. In particular these logical forms can be derived from surface structures by a rule of quantifier raising (as initially developed by Robert May; see May (1985)) by which a quantifier phrase moves out of its argument position to adjoin to a larger 
phrase containing that quantifier phrase at the level of surface form, to which (in Heim \& Kratzer's (1998) implementation) a predicate-abstraction operator has also affixed to bind the variable left behind as a trace of the movement. In short, this is the transformation that takes us from the English sentences in (17) and (18) to the logical forms of them represented there.

With this background in place, I am now in a position to say what, on the descriptions-as-predicates view, are the logical forms of sentences containing descriptions in argument position. I propose that like other determiner phrases, in particular quantifier phrases, descriptions undergo a process of raising, leaving behind a variable that gets bound in the process by a predicate-abstraction operator. ${ }^{10}$ The difference is that unlike quantifier phrases, descriptions slot into the predicative portion of a restricted quantifier:

(21) $[\ldots[\mathrm{a} /$ the $F] \ldots] \Longrightarrow[D E T:$ a/the $F] \hat{x}[\ldots x \ldots]$.

Here ' $[\ldots \xi \ldots]$ ' represents a sentence ${ }^{11}$ containing an argument position, represented by ' $\xi$ ', that's occupied by a description at the level of surface form. The occupant $D E T$ of the restricted quantifier is either an unpronounced determiner with either existential or generic force or an adverb of quantification occurring explicitly in the sentence. With respect to the latter case, I want to add two qualifications. First: DET can be an adverb of quantification only if the description occurs in an argument position of the verb modified by that adverb at the level of surface form. Second: where DET is an adverb of quantification explicitly occurring in the sentence, I take it to have moved out of its position in ' $[\ldots[\mathrm{a} / \mathrm{the} F] \ldots]$ ', so that it will not occur in ' $[\ldots x \ldots]$ '. An example should serve to illustrate:

(22) A runner hardly ever smokes.

Here we have the indefinite description 'a runner' occurring in the argument position of the verb 'smokes', which is (superficially) modified by an adverb of quantification 'hardly ever'. The rule represented in (21) allows for three logical forms, with their truth conditions spelled out and glossed as indicated:

(23) $\left[\emptyset_{\exists}:\right.$ a runner $] \hat{x} x$ hardly ever smokes,

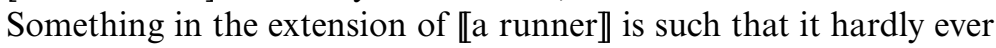
smokes,

Some runner hardly ever smokes;

(24) $\left[\emptyset_{G E N}:\right.$ a runner] $\hat{x} x$ hardly ever smokes,

It's generally true of a runner that it is such that it hardly ever smokes,

In general, runners hardly ever smoke; 
(25) [Hardly ever : a runner] $\hat{x} x$ smokes,

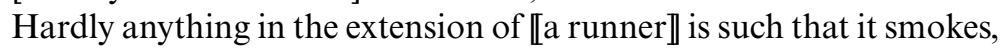
Hardly any runners smoke.

Note that the predicate 'smokes' plays a very different semantic role in (23) and (24) from the one it plays in (25). The difference can be captured by saying that 'smokes' in (23) and (24) seems to be a predicate that's true of a thing at a time just in case it's smoking at that time, whether or not that thing is a smoker; while 'smokes' in (25) is a predicate that's true of a thing at a time just in case it's a smoker at that time, whether or not that thing is smoking at that time. I'll describe the difference using the terms 'episodic' and 'habitual'. The predicate 'smokes' gets an episodic reading in (23) and (24), but a habitual reading in (25). In saying this I do not take myself to be committed to the claim that the word 'smokes' is ambiguous, only that predicates in which it occurs may have either an episodic or a habitual reading. We might for example say that 'smokes' invariably has the episodic meaning, but that it may be modified (i) by an explicitly-occurring adverb of quantificationleading to what I'll call a "frequency of episode" reading for the modified verb phrase "hardly ever smokes"; or (ii) by an unpronounced one with something like the meaning of 'generally', 'regularly', 'characteristically' or 'habitually'-leading to what I'll call the "habitual" reading for the phrase 'smokes'. I take it that (22) does have the three different truth conditions displayed above, and that the descriptions-as-predicates view scores a point against the Russellian in being able to account for them without positing any ambiguity in the indefinite description.

A similar variation in quantificational force also occurs with definite descriptions:

(26) The owner of an espresso machine rarely goes to bed early.

As before, the predicate 'goes to bed early' gets an episodic reading in the first two cases (leading to a "frequency of episode" reading for the modified verb phrase 'rarely goes to bed early'), but a habitual reading in the third case:

(27) $\left[\emptyset_{\exists}\right.$ : the owner of an espresso machine] $\hat{x} x$ rarely goes to bed early, Some (unique) owner of an espresso machine rarely goes to bed early;

(28) $\left[\emptyset_{G E N}:\right.$ the owner of an espresso machine $] \hat{x} x$ rarely goes to bed early,

In general, espresso-machine owners rarely go to bed early;

(29) [Rarely: the owner of an espresso machine] $\hat{x} x$ goes to bed early, Rare is the espresso-machine owner who goes to bed early. 
The important thing to note about this example is that it contains a definite description that can be true of more than one thing - despite the uniqueness condition I've built into the semantics of the definite article-because the uniqueness of ownership is relativized to individual espresso machines. This can be made explicit in the logical form by representing the indefinite 'an espresso machine' as taking its scope within the restricted quantifier but outside the definite article:

(30) $\left[D E T: \hat{x}\left[\emptyset_{\exists}:\right.\right.$ an espresso machine $] \hat{y} x$ (is) the owner of $\left.y\right] .^{12}$

If the definite description here weren't capable in principle of being true of more than one thing then it wouldn't make sense to quantify over those things satisfying it using adverbial quantifiers like 'generally', 'rarely', 'usually' and 'always'. The reason is that using one of these adverbial quantifiers to quantify over things of a given sort pragmatically generates the strong implication that there is more than one thing of that sort.

This brings to the fore an interesting feature of the treatment of generics on the descriptions-as-predicates view, which I'll briefly highlight before moving on to the next section. So far, genericity has been treated as resulting from a description's restricting an unpronounced determiner $\emptyset_{G E N}$ that has generic quantificational force. ${ }^{13}$ But this treatment will not work for those cases when a definite description is semantically required to have either a singleton or an empty extension but which is nonetheless used generically:

(31) The tiger is an animal that breeds well in captivity.

The two logical forms assigned to this sentence (only two because it does not contain an explicit adverb of quantification) are:

(32) $\left[\emptyset_{\exists}:\right.$ the tiger] $\hat{x} x$ is an animal that breeds well in captivity,

(33) $\left[\emptyset_{G E N}:\right.$ the tiger] $\hat{x} x$ is an animal that breeds well in captivity.

The second logical form here, the one with the generic, is perfectly wellformed and is semantically interpretable, but is ruled out on pragmatic grounds since 'the tiger' can be true of at most one thing. Yet the logical form with the existential quantifier doesn't seem to capture the generic truth conditions of (31). For all that's been said so far, given that 'tiger' is neither a plural nor a mass term, (31) is wrongly predicted to be true just in case there is exactly one tiger and it breeds well in captivity. But this is not obviously what (31) means. After all, breeding is not something a tiger can do on its own!

However, more can be said. Sharvy intended his generalization of Russell's theory of descriptions to account for definite descriptions with plurals and mass terms. But it, and its modification here, can also apply to the case of kind definite descriptions: cases where the nominal complement of the 
definite article, whether count or mass, has a "taxonomic" interpretation. For example, the common noun 'tiger' can receive both an individual interpretation and a taxonomic interpretation, as shown by the following:

(34) There are three tigers in this room; I hope they're not hungry;

(35) Three tigers went extinct in the last century: the Caspian, the Balinese, and the Javan.

If we take it that on its taxonomic interpretation the noun 'tiger' is a predicate true of every tiger-kind-leaving open just what kind of thing a tiger-kind is and also leaving open just which collections of tigers constitute a tigerkind, but allowing that a subspecies of tiger is a tiger-kind - then since kinds can be ranked according to a parthood-like relation, the relation of being $a$ sub-kind of, Sharvy's proposal provides us with a way of dealing with the genericity of the sort exhibited in (31). ${ }^{14}$ The definite description 'the tiger' in (31) will on the present proposal be a predicate true of just one thing, that tiger-kind of which every tiger-kind is a sub-kind-namely, the entire tiger species. ${ }^{15}$ In order to say that we've thereby captured the "generic" truth conditions of (31), we have to add that predicates like "has stripes" can be true of tiger-kinds as well as individual tigers.

The point being emphasized here is that my analysis of descriptions as predicates includes two different treatments of genericity for definite descriptions, depending on whether they are at most singly applicable, i.e., true of at most one "thing," or are multiply applicable, i.e., in principle true of more than one thing, as a result (for example) of containing an embedded indefinite. In the former case, we have existential quantification over a kind-level predicate; in the latter case we have generic quantification over an individual-level predicate:

(36) The mystery novel is popular,

$\left[\emptyset_{\exists}\right.$ : the mystery novel $] \hat{x} x$ is popular,

(Taxonomic interpretation for 'mystery novel');

(37) The author of a mystery novel is (generally) popular, $\left[\emptyset_{G E N}:\right.$ the author of a mystery novel] $\hat{x} x$ is popular, ${ }^{16}$ (Individual interpretation for both 'author' and 'mystery novel').

I should at this point reiterate something mentioned only in passing above, namely, that I also take bare plural noun phrases to be yet another kind of predicate nominal, so that genericity with bare plurals is to be dealt with in the same manner as indefinite descriptions and multiply-applicable definite descriptions. The generic reading of 'tigers have stripes' (which is the only reading in the absence of special intonational emphasis) is accounted for by assigning to this sentence the following logical form:

(38) $\left[\emptyset_{G E N}:\right.$ tigers $] \hat{x} x$ have stripes. 
Although it's not superficially apparent, it's worth noting that there is also an analogous difference, albeit less marked than in the case of singly- versus multiply-applicable definites, between the treatment of singular-indefinite generics and that of bare-plural generics. Both involve generic quantification on the treatment proposed here, but in the singular-indefinite case this is generic quantification over individuals, while in the bare-plural case this is generic quantification over pluralities of individuals. I'd like to think that this difference could be appealed to in accounting for at least one important difference between the two. ${ }^{17}$ The distinction is between the following:

(39) Tigers are extinct,

(40) A tiger is extinct.

'Extinct' is a predicate that can only be true of a species (or subspecies), not of individual members of the species. Yet for some reason it is combinable with the bare plural even on its non-taxonomic interpretation, while combinable with the singular indefinite only on its taxonomic interpretation. This could be handled on the present view by allowing "kind-level" predicates like 'extinct' to be true of pluralities as well as kinds. The bare-plural sentence would then be interpreted on one of its false but sensible readings as generic quantification over tiger-pluralities, and on its other false but sensible reading as generic quantification over tiger-kind-pluralities; ${ }^{18}$ while the second sentence would be interpreted on its sensible (and true) reading as existential quantification over tiger-kinds.

Let me wrap up this section by summarizing the main points so far. Definite and indefinite descriptions invariably have predicate-type semantic values. When one occurs in an argument position of a predicate, it undergoes a process that's like quantifier-raising except that it slots into the predicative (restrictor) portion of the restricted quantifier. The quantifier portion of this restricted quantifier is either an unpronounced quantificational determiner with either existential or generic force, or an adverb of quantification explicitly occurring in the sentence. Definite descriptions, however, except in those special cases where they are multiply-applicable (for example because they contain an embedded indefinite), can restrict only an existential quantifier, the other quantifiers being ruled out on pragmatic grounds. ${ }^{19}$ Generic readings for singly-applicable definite descriptions result not from generic quantification but from a taxonomic reading for the predicative complement of the definite article.

\section{Descriptions with Adverbs of Quantification}

I take it that one of the most forceful arguments for the descriptions-aspredicates view stems from the fact that descriptions (now including bare 
plurals under this heading) interact with adverbs of quantification in a way that quantifier phrases do not. In "Descriptions as Predicates" (§VII) I claimed that the a-sentences in the sets of examples below are multiply ambiguous while the $b$-sentences are unambiguous.

(41) a. The owner of an espresso machine rarely prefers tea to coffee,

b. Most owners of an espresso machine rarely prefer tea to coffee,

c. Joe rarely prefers tea to coffee,

d. Joe prefers tea to coffee.

(41a) can be understood in any of the three ways so far predicted by the analysis: as saying (i) that some one espresso-machine owner has the "frequency of episode" property attributed to Joe by (41c) - represented as:

$\left[\emptyset_{\exists}:\right.$ the owner of an espresso machine $] \hat{x} x$ rarely prefers tea to coffee;

(ii) that espresso-machine owners in general have the frequency-of-episode property attributed to Joe by (41c) — represented as:

$\left[\emptyset_{G E N}:\right.$ the owner of an espresso machine] $\hat{x} x$ rarely prefers tea to coffee;

or (iii) that few owners of an espresso machine have the "habitual" property attributed to Joe in (41d) - represented as:

[rarely : the owner of an espresso machine] $\hat{x} x$ (habitually) prefers tea to coffee.

(41b), in contrast, is unambiguous, and can only mean that most espressomachine owners have the frequency-of-episode property.

Analogous claims were made about the interaction of indefinite descriptions, bare plurals, and plural definites with adverbs of quantification:

(42) a. A Scandinavian rarely has brown eyes,

b. Every Scandinavian rarely has brown eyes,

c. Joe rarely has brown eyes,

d. Joe has brown eyes;

(43) a. Philosophers sometimes smoke,

b. Both philosophers sometimes smoke,

c. Joe sometimes smokes,

d. Joe smokes;

(44) a. The parents of a toddler usually have little time for relaxation,

b. Many parents of a toddler usually have little time for relaxation,

c. Joe usually has little time for relaxation,

d. Joe has little time for relaxation. 
It is true that (42a) can't equally naturally be read as having any of the three readings (so far) assigned to it by the descriptions-as-predicates analysis. But this is obviously to be explained on pragmatic grounds: having brown eyes tends to be a permanent property of the things that have it, which is why we most naturally read (42a) as saying that few Scandinavians have brown eyes. The other readings (so far) assigned to this sentence by the descriptionsas-predicates analysis involve attribution of the very strange frequency-ofepisode property attributed to Joe in (42c) (strange, at least, in the days before tinted contact lenses) and are therefore less salient. (42b), in contrast (I claimed), is unambiguous and can only mean that every Scandinavian has the strange frequency-of-episode property.

I took these sets of examples to provide confirmation for the descriptionsas-predicates view and a strong argument against Russellianism. The confirmation for the descriptions-as-predicates view stems from the fact that it smoothly accounts for the "quantificational variability effects" of descriptions (definite and indefinite, singular and plural) displayed in the a-sentences in (41-44). Moreover, I take these sets of examples to provide confirmation not just for the predicate view as contrasted with the uniform Russellian view, ${ }^{20}$ but also for the predicate view as contrasted with a "type-shifting" view, as proposed by Barbara Partee (1987) and accepted by virtually all linguists who commit to a view on the matter - on which descriptions are systematically and predictably ambiguous between a type $\langle e, t\rangle$ interpretation when occurring in predicative position, and either a type $e$ or a type $\langle\langle e, t\rangle, t\rangle$ interpretation when occurring in argument position. For if descriptions in argument position at least some of the time have to receive a type $\langle e, t\rangle$ interpretation in order to serve as the restrictor of an adverb of quantification, then since allowing them to uniformly take a type $\langle e, t\rangle$ interpretation provides a smooth way of capturing the further ambiguity between existential and generic readings in a way that, as we saw in the last section, provides a nice account (given Sharvy's important work and the extension of it here to kind-level descriptions) of a wide variety of semantic facts about generic statements, we have no good reason to adopt type-shifting.

The argument against Russell's theory of descriptions stems from the fact that however its proponents may ultimately explain the quantificational variability effects that look troubling for it, the difference between the aand b-sentences in (41-44) with respect to the existence of quantificational variability effects points to an important disanalogy between descriptions and quantifier phrases. Call this the quantificational-variability argument against Russellianism.

It's been stressed to me that it was not quite right to say that quantifier phrases don't ever interact with adverbs of quantification in the way that descriptions do. ${ }^{21}$ The adverbs of quantification in the b-sentences above may obligatorily modify the verb phrase in those sentences, but there are 
very closely related sentences that don't place this restriction on the adverbs in them.

Given the right conversational setup, the adverbs of quantification in (4547) can be understood as quantifying over some conversationally salient type of situation or event rather than as modifying the main verb. For example, imagine that each year I have a party to which I invite owners of various types of kitchen machines: orange-crushing machines, apple-coring machines, espresso machines, etc. In a conversation where it is under discussion that I annually hold such a party, (45) can naturally be interpreted as meaning that it's occasionally the case that at one of these parties some of the espressomachine owners at that party prefer (habitually) tea to coffee:

(45) Some of the espresso-machine owners occasionally prefer tea to coffee.

Given discussion of an annual party to which I invite people from various European countries, (46) can with a little strain be interpreted as meaning that it's rarely the case at one of these parties that all of the Scandinavians at that party have brown eyes:

(46) All of the Scandinavians rarely have brown eyes.

And, just to round things out, given discussion of an annual party to which I invite two people from each academic department in my university, (47) can easily be interpreted as meaning that it's sometimes the case at one of these parties that both of the philosophers at that party (habitually) smoke:

(47) Both of the philosophers sometimes smoke.

Presumably, the reason these quantification-over-parties readings become available - given the right conversational background - with the partitives above (which are, roughly speaking, "blank-of-the-blank"-phrases) is that partitives for some reason already require some contextually salient domain to quantify over. "Most of the philosophers called me last night," said in the absence of such a contextually salient domain's having been provided is rightly greeted with the question, "Most of which philosophers?" The domainproviding property thing at my party that needs to be contextually salient for the use of the partitive to be appropriate stands out as being also saliently available to restrict (in some yet-to-be-spelled-out way) the domain of an adverb of quantification. ${ }^{22}$

So the question is, does the existence of these "extra" readings - let's call them situation-readings - for the partitive counterparts of the b-sentences in (41-44) undermine the quantificational-variability argument against Russellianism? The point I wish to make here is that it does not. The reason is that just as there is an extra, situation reading for the sentences in (45-47), 
neglected in Fara (2001), on which the quantifier phrases can vary their denotation with respect to the different situations being quantified over, there is also an exactly analogous extra, situation reading - equally neglected in the earlier discussion - for the a-sentences containing descriptions in (41-44). For example, in a situation in which it's under discussion that I have an annual party to which I invite, for each of a number of kinds of kitchen machine, one person who owns a machine of that kind, (41a) (repeated here) can be understood as saying that it is rarely the case at one of these parties that the owner of an espresso machine at that party prefers (habitually) tea to coffee.

(41) a. The owner of an espresso machine rarely prefers tea to coffee.

We might wish to describe this as a case in which the description "interacts" with the adverb of quantification in the sense that this interpretation requires us to evaluate the description in some or all of a variety of situations being quantified over by the adverb. But it is not a case in which the description interacts with the adverb in the special way provided by the descriptions-aspredicates view, namely, as a restrictor of it.

In short, we have on the one hand that for each way of interpreting a sentence with a quantifier phrase in the argument position of a predicatewhether an adverb of quantification explicitly occurs in the sentence or not, there is an exactly analogous way of interpreting the corresponding sentence with a description in the place of the quantifier phrase. This is just as we'd expect, since the Russell/Sharvy analysis of descriptions as quantifier phrases yields truth conditions that turn out to be a special case of those proposed by the descriptions-as-predicates view, namely, the case of a description restricting an unpronounced determiner with existential force. On the other hand, there are ways of interpreting a sentence with a description in the argument position of a predicate that have no analogous interpretation when the description is replaced with a genuine quantifier phrase. This fact suggests that however the Russellian might account for the interpretations we've accounted for here as an adverb being restricted by a description qua predicate, that account will inevitably predict that other quantifier phrases interact with adverbs of quantification in a way that they just don't seem to. A particularly striking minimal pair is the following:

(48) A Scandinavian usually has blue eyes,

(49) Some Scandinavian usually has blue eyes.

The preferred interpretation for (48) intuitively involves quantification over individual Scandinavians, with the force of the quantification being that given by the adverb 'usually'. The descriptions-as-predicates view captures that reading - which I'll tendentiously call the quantification-over-individuals reading - in exactly the way suggested by intuition: by allowing the adverb to 
quantify over the individuals in the extension of the indefinite description by forming a restricted quantifier with it: '[usually : a Scandinavian]'. ${ }^{23}$ Crucially, there is no quantification-over-individuals reading for (49); it cannot mean that most Scandinavians have blue eyes.

We'll return to this latter fact in just a moment, but let's first ask: how might an ardent Russellian capture the quantification-over-individuals interpretation for the sentence with the indefinite description? Our prediction was that any proposal along these lines would incorrectly assign the same interpretation to (49). One sort of proposal involves adverbial quantification over "minimal" situations. Two proposals in this vein are found in Heim (1990) and von Fintel $(1994,2004) .{ }^{24}$ One important feature of the "situations" deployed in these proposals is that they can have situations as parts and can be parts of situations. A "minimal" situation in which it's the case that $\Phi$ (call this "a $\Phi$-situation") is a $\Phi$-situation that has no $\Phi$-situation as a proper part. The intuitive idea should be clear enough for the purposes of our discussion here. ${ }^{25}$ The general form of von Fintel's version of the proposal, applied to a sentence that can be rewritten as one with the form 'ADV: $\Phi$ ' is that it gets the following truth-conditions: ADV-many minimal $\Psi$-situations are a part of a minimal $(\Phi \wedge \Psi)$-situation, where $\Psi$ is a restriction provided by the conversational context. Now the paraphrase of the analysis of (48) is:

(50) Most minimal situations in which there's a Scandinavian are part of a minimal situation in which: a Scandinavian has blue eyes. ${ }^{26}$

Note that there's a one-one correspondence between Scandinavians and minimal situations in which there's a Scandinavian. Quantification over minimal situations in which there's a Scandinavian for this reason mimics the effect of regular quantification over individual Scandinavians. This is not a mere trick, however; once quantification over situations is adopted, and once it's allowed that situations are parts of other situations, and, moreover, that any situation that contains a $\Phi$-situation as a part must itself be a $\Phi$-situation, the domain of quantification must be restricted to minimal situations in order to avoid what we'd intuitively think of as counting the very same situation multiple times. The reason for having the "larger" situation also be a minimal situation is equally well motivated; for if the larger situation weren't minimal, the existence of a single blue-eyed Scandinavian would suffice to render the entire claim true. Intuitively, we want the blue-eyed Scandinavian in the larger situation to be the very Scandinavian that's in the smaller situation. The indefinite description 'a Scandinavian' can now be interpreted in the Russellian manner as an existential quantification. The Russellian can in this way account for the interaction of descriptions with adverbs of quantification.

It's now time to return to the pressing question for the Russellian: why is it that (49) does not allow a quantification-over-individuals reading while (48) does? 
(48) A Scandinavian usually has blue eyes.

(49) Some Scandinavian usually has blue eyes.

As far as I know, von Fintel is the only one to explicitly address this problem. But his remarks are very brief, and meant only to suggest an avenue for further investigation. He says that 'some', unlike ' $a$ ', is "inherently partitive" and so that the situations being quantified over by the adverb each contain all relevant Scandinavians. The quantifier-variability effect "will not arise," he writes, "because it is a side-effect of quantifying over very small situations containing only one [Scandinavian] each" (2004, p. 163). The suggestion is that 'some Scandinavian' is like 'at least one of the Scandinavians' in that it requires for its felicitous use a contextually salient set of Scandinavians; but unlike it, presumably, in allowing that set to be a singleton. In the absence of such a contextually salient set of Scandinavians, a user of one of these partitive phrases would be appropriately greeted with the question, "Which Scandinavians are you talking about?" The further suggestion is that if, for example, we're talking about the Scandinavians at my annual party of Europeans, then the minimal situations being quantified over by the adverb must each contain enough of one of these parties to have all the Scandinavians at that party in it (as well as enough of the party, I presume, to be a party). The truth-conditions that result from this are just equivalent to what we earlier called the situation-reading for the sentence. There's no mimicking of quantification over individuals because there's not a one-one correspondence between these minimal situations and Scandinavians.

My reply to this suggestion consists of two main parts. The first point is that although I agree (I think) that there is a partitive-like use of 'some'phrases, the availability of this partitive-like use is extremely sensitive to subtle variations in intonation. In any case it's not always there, since it's perfectly acceptable to initiate a conversation with an out-of-the-blue use of a 'some'phrase. Compare the following.

(51) Guess what I just heard. One of the Scandinavians occasionally has purple eyes.

(Appropriate response: which Scandinavians are you talking about?)

(52) Guess what I just heard. Some Scandinavian occasionally has purple eyes.

(Appropriate response: Do you mean to say that he or she doesn't always have purple eyes?)

I've substituted a more news-worthy predicate in the example, in order to render it plausible as a conversation-opener.

The second point is that the problem is not to be accounted for by attributing special properties to 'some'; the problem is much more widespread than that. Consider the following: 
(53) Few Scandinavians usually have blue eyes,

(54) Hardly any Scandinavians usually have blue eyes.

Both of these sentences clearly have a reading involving attribution of the strange frequency-of-episode property. But if we apply the situation approach to these sentences we get the following: Most minimal situations in which there are few (hardly any) Scandinavians are a part of a minimal situation in which few (hardly any) Scandinavians have blue eyes. But this is roughly equivalent (it seems to me) to the claim that most Scandinavians have blue eyes; clearly not an interpretation for (53) or (54)!

The upshot is that our prediction has been borne out. The situation-based approach to preserving Russell's theory of descriptions, although successful insofar as it is capable of mimicking the quantification-over-individuals readings for descriptions with adverbs of quantification, is unsuccessful in that it does not account for the differential behavior between descriptions and genuine quantifier phrases in this regard.

By way of closing I'd like to address one question still left unanswered, namely, how on the descriptions-as-predicates view are we to handle those uses of adverbs of quantification that $d o$ intuitively involve quantification over situations? These were the "extra" readings for the a-sentences in (41-44) as uttered, for example, against a background discussion of my annual parties of this or that type. The question is more sharply focused by considering a singly-applicable definite description with an adverb of quantification. The following example is discussed by Jason Stanley (2002):

(55) The customer is always right.

One could, I suppose, utter this sentence to say of one particular (salient) customer that that customer is perpetually right. But on its natural, almost proverbial, reading, it's a claim about any number of customers. Because this is a singly-applicable definite description, it cannot sensibly restrict the adverb 'always', since this would yield something like a false "scalar" implicature to the effect, in essence, that this singly-applicable definite description multiply applies. So we cannot account for the natural reading of this sentence by assigning it the logical form: '[always : the customer] $\hat{x} x$ is right'. But note that what's being claimed here is not intuitively even like a quantificationover-individuals reading for the adverb. We don't say, in uttering this sentence, that every customer is habitually right. Rather, we say that every customer in a certain type of situation is right in that situation. What's the relevant type of situation? Something like a dispute between customer and employee. It looks like we need to be able to accommodate something like the situation-based approach in order to account for sentences like these (as well as the situationreadings for the a-sentences in $(41-44)$ ). But there is nothing inherently undermining in that. The semantics proposed here for descriptions will have 
to modularly mesh with semantic accounts for any other type of phrase it can co-occur with. ${ }^{27}$

Let's look at Stanley's proposal. ${ }^{28} \mathrm{He}$ argues that we can account for this sentence as a case of binding into a nominal restriction, a device which, he proposes, accounts for a wide and somewhat disparate-seeming variety of cases of context-dependence, including especially quantifier-domain restriction: 29

(56) Always $_{i}$ : the customer $f(i)$ is right.

Here ' $f$ ' occurs as a variable that in the context gets assigned a function from objects to sets of individuals. Intuitively, it's a function which, given a dispute as argument, yields the set of parties to that dispute as value. The extension of 'customer $f(i)$ ', for a particular value of ' $i$ ', is the intersection of the extension of 'customer' with the set $f(i)$. Since the resulting intersection is supposed to be a singleton set, the Russellian analysis of descriptions could be maintained in face of this example. One potential difficulty here, though, is that if 'Always,' ranges over everything there is, then $f(i)$ will either be undefined for most values of ' $i$ ', in which case I'd think that the sentence would be truth-valueless, or it will yield, for many values of $i$, sets that don't have any customers in them at all or even any things that could be right or wrong, in which case I'd think that the sentence would be false. In any case, putting this worry aside, this proposal in its bare-bones form needn't be viewed as an alternative to the situation-based approach, but could rather be viewed as one way of implementing it.

The point I wish to make here by way of closing is that the descriptionsas-predicates view can also make use of this form of nominal restriction in order to capture situation-readings for adverbs of quantification. Let's think of the ' $i$ ' in a nominal restriction as occurring in an argument position; this is natural if we think of the function $f(\xi)$ assigned to ' $f$ ' as doing the work of a prepositional phrase such as 'in $(\xi)$ '. If ' $i$ ' is left free and is assigned an entity as semantic value (in the context), then it can be interpreted in situ. While if it is assigned something of type $\langle e, t\rangle$ or $\langle\langle e, t\rangle, t\rangle$, then it must raise out of argument position. So suppose it gets assigned as value the value of a description such as 'a dispute between customer and employee'_-'a dispute' for short. Then on the description-as-predicates view, we can assign the following surface and logical forms to the sentence, using expressions in place of variables just to indicate what values those variables are getting assigned by context:

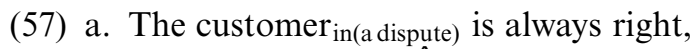

b. [Always: a dispute] $\hat{i}$ the customer ${ }_{\text {in(i) }}$ is right, ${ }^{30}$

c. [Always: a dispute] $\hat{i}\left[\emptyset_{\exists}:\right.$ the customer $\left.r_{\text {in }(i)}\right] \hat{x} x$ is right.

This says what we want it to say: that every dispute (between customer and employee) is an $i$ such that the customer in $i$ is right. ${ }^{31}$ One advantage this 
has over the situation-based approach is that in quantifying over disputes, rather than minimal situations, we can retain a relatively simple semantics for the adverb, rather than pack into its lexical meaning, as is typically done on the situation-based approach, the notions of being a minimal $\Phi$-situation and being an extension of a situation. This will remain an advantage only to the extent that nominal restriction is sufficiently widespread and flexible to be used in this way. ${ }^{32}$

\section{Notes}

1. Throughout, I'll use single quotes for both name-forming quotation and quasiquotation, and will drop the quotes in some cases for the sake of readability.

2. For a more developed and formal presentation of this idea, consult Link (1983, for example).

3. For this proposal, along with independent motivations for it, see for example Ladusaw (1982), Link (1987), and Krifka (1999).

4. For definite-numeral combinations I assume the syntactic structure [the [num $F$ ] rather than the structure [the num] $F]$.

5. Here I represent pluralities as sums, which would have annoyed Sharvy given his insistence (Sharvy 1980, p. 620) that, e.g., the men in Auckland are men, and hence essentially a plurality, rather than some one single, mysterious sort of entity.

6. This is noted by George Wilson (1978, p. 51f.) and James Higginbotham (1987), and is discussed in section IV of Graff (2001).

7. The syntax is reminiscent of that for Robert Stalnaker's (1977) language $\hat{L}$, in which a logical formula such as $\forall \hat{x} F x$ is parsed as consisting of the quantifier $\forall$ and the complex predicate $\hat{x} F x$ formed by predicate abstraction. It extends the syntax of $\hat{L}$ in allowing restricted as well as unrestricted quantifiers.

8. In saying this, I blur the distinction between a set and its characteristic function on the relevant domain, since Barwise \& Cooper take a generalized quantifier to be a set of sets of individuals.

9. This generalized quantifier can be obtained compositionally, moreover, from the semantic value of the determiner and that of $F$, by assigning the determiner 'every' the appropriate type $\langle\langle e, t\rangle,\langle\langle e, t\rangle, t\rangle\rangle$ function. Consult Barwise \& Cooper (1981, $\S 2)$ or Heim \& Kratzer (1998, ch. 6) for further details and elaboration.

10. A brief remark about terminology: in calling descriptions "determiner phrases" I assume that the definite and indefinite articles, as well as numeral words, are determiners, even though on my proposal they have the semantics of a predicate modifier. I reserve the word 'quantifier' for those determiners with semantic type $\langle\langle e, t\rangle,\langle\langle e, t\rangle, t\rangle\rangle$, and 'quantifier phrase' for phrases of type $\langle\langle e, t\rangle, t\rangle$. 'Restricted quantifier' is the term I use for those expressions that represent quantifier phrases in the language being used to represent logical forms.

11. Or other phrase that has a type $t$ semantic value at the level of logical form.

12. Essentially, we have allowed the (restricted quantifier restricted by the) indefinite description to adjoin to something other than a sentence, namely, to the definite description in which it is embedded. This sort of quantifier raising had already been proposed by May (1985) under the heading of "inverse linking". Allowing it requires some complications of either the syntax or the semantics. Rather than 
complicate the semantics by allowing for type-shifting of quantifier phrases, I prefer to complicate the syntax. I was rather hand-wavy about this in Graff (2001); so let me be more explicit here. I adopt the kind of solution for interpreting these embedded determiner phrases that's outlined by Heim \& Kratzer (1998, ch. 8). The solution involves positing an empty subject PRO in the definite description, which, although it has no semantic value itself, can act as if it had one by raising and leaving a bound variable as trace. So the internal logical form of the definite description here is derived as follows:

[DPPRO the owner of an espresso machine] $\Longrightarrow$

$\left[\mathrm{DP}\left[\emptyset_{\exists}\right.\right.$ : an espresso machine $\hat{y}[\mathrm{DP} P R O$ the owner of $\left.y]\right] \Longrightarrow$

[DPPRO $\hat{x}\left[\emptyset_{\exists}:\right.$ an espresso machine] $\hat{y}[\mathrm{DP} x$ the owner of $\left.y]\right]$.

This is perfectly interpretable given the semantic rules already provided. Together with the assumption that 'PRO' is semantically vacuous, these rules yield a predicate that is true of a thing just in case there's some espresso machine it uniquely owns. Some may balk, of course, at the uniqueness requirement here; thinking that (26), on any of its readings, is as much about those who jointly own an espresso machine as it is about those who uniquely own one. I sympathize with the worry, but I suspect that it can be assuaged without overhauling the view, yet I won't attempt to do that here since I think that the issues involved are detachable from those of primary concern in this paper. For interesting discussion of the history of treatments of inverse linking and the importance of it to the development of syntax and its interface with semantics, see May \& Bale (2006).

13. I don't take a stand on what exactly the meaning of the generic quantifier is, at least not as stated in terms that don't involve using it; but I take myself nonetheless to be providing truth conditions for logical forms containing it by using it itself, since I take it that we have, to a sufficiently large extent anyway, an intuitive grasp of its meaning. I call $\emptyset_{G E N}$ a quantifier, since by this I just mean an expression of type $\langle\langle e, t\rangle,\langle\langle e, t\rangle, t\rangle\rangle$, that is, an expression that combines with a one-place predicate to form an expression of type $\langle\langle e, t\rangle, t\rangle$. Ascertaining its contribution to truth-conditions is a notoriously difficult matter. I'll refer the reader to two reasonably plausible recent accounts, both containing good overviews of the literature on this issue: Cohen (1999) and Leslie (n.d.).

14. I take it that the relation of being a sub-kind of is definitely not a subspecies of the parthood or some-of relation, and that for that reason we cannot take ' $\leq$ ' in our statement of the semantics of the definite article to univocally express this relation. Rather, we must let it variably stand for different sorts of parthood-like relations depending on the structure of the extension of the predicate it operates on. We cannot let it stand univocally for some more general parthood-like relation of which the parthood relation as well as the sub-kind relation are both subspecies, because of the fact discussed above - that tables, for example, can have other tables as parts.

15. The discussion of this in Fara 2001 (pp. 30-31) is flawed in that it does not explicitly make use of Sharvy's maximality operation, as it should have. The discussion there was a holdover from earlier versions of the view on which I'd not yet adopted Sharvy's generalization of Russell's uniqueness condition, and I recognized the oversight only after it became too late to make revisions. Roberto 
Zamparelli (1998) had already proposed the same idea in work I've only since become aware of.

16. Here I suppress the internal logical form of the definite description inside the restricted quantifier for the sake of readability. Spelled out, the whole thing becomes:

$\left[\emptyset_{G E N}: \hat{y}\left(\left[\emptyset_{\exists}:\right.\right.\right.$ a mystery novel $] \hat{z} y(($ is) the author of $\left.z))\right] \hat{x} x$ is popular;

which is worth emphasizing so that it is clear that this is a multiply-applicable definite description.

17. This much-discussed difference is observed in Lawler's (1973) dissertation. For more recent discussion of it, see for example Greenberg (2002) and the references cited there.

18. Three subspecies of tiger went extinct in the last century; there are five remaining ones (all endangered, three on the brink of extinction).

19. The fact that definite descriptions are subject to quantificational-variability effects has pretty much been ignored or gone unnoticed. I suspect that this is because it's only multiply-applicable definite descriptions that are capable of exhibiting this genericity.

20. As vigorously defended by Stephen Neale (1990).

21. This has been stressed to me in discussion by Jeffrey King and Jason Stanley, and also in a presentation by Berit Brogaard (2005).

22. Partitives aren't required in order to get a quantification-over-situations reading for quantifier phrases with adverbs of quantification. For example:

- All philosophers in the department sometimes attend an APA meeting;

- Some student who procrastinates usually fails.

The tentative generalization is that we get a quantification-over-situations reading for these sentences because the sentences themselves raise to salience a type of situation, either by mentioning it explicitly (APA meetings) or by using an implicitly relational phrase ('fail') that has a type of situation (a class, say) as a relatum. The first example was given to me by King, the second by Brogaard.

23. The descriptions-as-predicates view shares this advantage with Lewis's (1975) original proposal, and the developments of it instigated by Kamp (1981) and Heim (1982).

24. The proposal Neale sketches (1990, pp. 247-251) can be viewed as a start in this same direction. I should mention that Heim and von Fintel explicitly commit to Russellianism only about indefinite descriptions.

25 . It seems to me that these situations are very much like states of affairs that obtain.

26. Since $\Phi$ in this case entails $\Psi$, we can just re-write $(\Phi \wedge \Psi)$ as $\Phi$. I should mention that von Fintel himself would probably not accept this paraphrase (though I suspect that Heim would) since he implies that a bare minimal situation in which there's a Scandinavian is not sufficiently "situation-like" to serve as a contextual restriction for an adverb of quantification, and would apparently prefer instead to quantify over minimal situations in which we're "encountering" or "sampling" Scandinavians (2004, p. 163). I don't think this is a promising tactic, in part for the reason discussed by Lewis with respect to his example about quadratic equations, but also because it requires that we the encounterers in these situations are not ourselves blue-eyed Scandinavians. 
27. This point is well-made throughout Neale's (1990) Descriptions (with respect to his favored theory, of course).

28. See pp. $386 f$.

29. See Stanley \& Szabó (2000).

30. In order for this to be in keeping with the requirement that the description restricting an adverb occur in the argument position of the verb phrase superficially modified by that adverb, we have to think of 'right' as it occurs here as really meaning something like 'right in $i$ ', which seems desirable.

31. Or: 'is right in $i$ '; see the preceding footnote.

32. For discussion of matters relevant to this paper I am especially indebted to Berit Brogaard, Paul Elbourne, Michael Fara, Irene Heim, Jeffrey King, Robert May, Daniel Rothschild and Jason Stanley.

\section{References}

Barwise, Jon and Cooper, Robin. (1981) 'Generalized Quantifiers and Natural Language', Linguistics and Philosophy 4: 159-219.

Brogaard, Berit. (2005) Russell's Theory of Descriptions vs. the Predicative Analysis: a Reply to Graff. Presentation to the Eastern Division meeting of the American Philosophical Association, New York, December 2005.

Cohen, Ariel. (1999) Think Generic!, CSLI Publications, Stanford, CA.

Fara, Delia Graff. (2001) 'Descriptions as Predicates,' Philosophical Studies 102(1): 1-42. Originally published under the name 'Delia Graff'.

von Fintel, Kai. (1994) Restriction on Quantifier Domains, PhD thesis, University of Massachusetts, Amherst.

(2004) 'A Minimal Theory of Adverbial Quantification', in H. Kamp and B. Partee, eds., Context-Dependence in the Analysis of Linguistic Meaning, Elsevier Ltd, Oxford, pp. 137-75.

Greenberg, Yael. (2002) 'Two Types of Quantificational Modalized Genericity, and the Interpretation of Bare Plural and Indefinite Singular NPs', in B. Jackson, ed., Proceedings from SALT XII, Cornell University, CLC Publications, Ithaca, NY, pp. 104-23.

Heim, Irene. (1982) The Semantics of Definite and Indefinite Noun Phrases, PhD thesis, University of Massachusetts, Amherst.

(1990) 'E-Type Pronouns and Donkey Anaphora,' Linguistics and Philosophy 13(2): $137-77$.

Heim, Irene and Kratzer, Angelika. (1998) Semantics in Generative Grammar, Blackwell, Oxford. Higginbotham, James. (1987) 'Indefiniteness and Predication', in Eric J. Reuland and Alice G. B. ter Meulen, eds., The Representation of (In) definiteness, MIT Press, Cambridge, MA.

Kamp, Hans. (1981) 'A Theory of Truth and Semantic Representation', in J. Groenendijk, T. Janssen and M. Stokhof, eds., Formal Methods in the Study of Language, Mathematical Centre Tracts 135, Mathematisch Centrum, Amsterdam, pp. 277-322.

Krifka, M. (1999) 'At Least Some Determiners Aren’t Determiners', in K. Turner, ed., The semantics/pragmatics interface from different points of view, Elsevier, pp. 257-91.

Ladusaw, William. (1982) 'Semantic Constraints on the English Partitive Construction', in D. Flickinger, M. Macken and N. Wiegand, eds., Proceedings of the First West Coast Conference on Formal Linguistics, Linguistics Department, Stanford University, Stanford, pp. 231-42.

Lawler, John. (1973) Studies in English Generics, PhD thesis, University of Michigan, Ann Arbor. 
Leslie, Sarah-Jane. (n.d.) Generics: Cognition and Acquisition. Unpublished MS., Princeton University.

Lewis, David. (1975) 'Adverbs of Quantification', in E. Keenan, ed., Formal Semantics of Natural Language, Cambridge University Press, Cambridge, England, pp. 3-15.

Link, Godehard. (1983) 'The Logical Analysis of Plurals and Mass Terms', in R. Bäuerle, C. Schwarze and A. von Stechow, eds., Meaning, Use, and Interpretation of Language, Walter de Gruyter, Berlin, pp. 302-23.

(1987) 'Generalized Quantifiers and Plurals', in P. Gärdenfors, ed., Generalized Quantifiers, Studies in Linguistics and Philosophy, D. Reidel, Dordrecht, pp. 151-80.

May, Robert. (1985) Logical Form, Linguistic Inquiry Monographs, MIT Press, Cambridge, MA.

May, Robert and Bale, Alan. (2006) 'Inverse Linking', in M. Everaert and H. C. V. Riemsdijk, eds., The Blackwell Companion to Syntax, Blackwell, Oxford.

Neale, Stephen. (1990) Descriptions, MIT Press, Cambridge, MA.

Partee, Barbara. (1987) 'Noun Phrase Interpretation and Type-Shifting Principles', in J. Groenendijk, D. de Jongh and M. Stokhof, eds., Studies in Discourse Representation Theory and the Theory of Generalized Quantifiers, Vol. 8 of Groningen-Amsterdam Studies in Semantics, Foris Publications, pp. 115-43.

Roberts, Craige. (2003) 'Uniqueness in Definite Noun Phrases,' Linguistics and Philosophy 26: 287-350.

Russell, Bertrand. (1905) 'On Denoting,' Mind 14: 479-93.

Sharvy, Richard. (1980) 'A More General Theory of Definite Descriptions,' Philosophical Review 89(4): $607-23$.

Stalnaker, Robert. (1977) 'Complex Predicates,' The Monist 60(3): 327-39.

Stanley, Jason. (2002) 'Nominal Restriction', in G. Preyer and G. Peter, eds., Logical Form and Language, Oxford University Press, Oxford.

Stanley, Jason and Szabó, Zoltán Gendler. (2000) 'On Quantifier Domain Restriction,' Mind and Language 15: 219-61.

Wilson, George. (1978) 'On Definite and Indefinite Descriptions,' Philosophical Review 87: 4876.

Zamparelli, Roberto. (1998) 'A Theory of Kinds, Partitives and OF/Z Possessives', in A. Alexiadou and C. Wilder, eds., Possessors, Predicates and Movement in the Determiner Phrase, Vol. 22 of Linguistics Today, John Benjamins, Amsterdam, pp. 259-301. 
Copyright of Philosophical Issues is the property of Blackwell Publishing Limited and its content may not be copied or emailed to multiple sites or posted to a listserv without the copyright holder's express written permission. However, users may print, download, or email articles for individual use. 